\title{
Changes in diet quality 6 and 12 months post-intervention: the Healthy Habits, Healthy Girls: a Brazilian study
}

\author{
Mudanças na qualidade da dieta em 6 e em 12 \\ meses pós-intervenção: Hábitos Saudáveis, \\ Meninas Saudáveis: estudo brasileiro
}

\author{
Ana Carolina BARCO LEME' (iD) 0000-0003-2782-4301

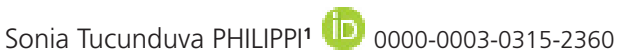

Regina Mara FISBERG ${ }^{1}$ (ID) 0000-0002-4490-9035

\section{A B S T R A C T}

\section{Objective}

To determine the sustainability of food quality in an obesity-prevention strategy for adolescent girls.

\section{Methods}

The study is a randomized controlled trial with 253 girls (Mean=15.61, 95\% Confidence Interval 15.51-15.72) enrolled in 10 vocational schools in São Paulo. The diet intake was determined using a "Food Frequency Questionnaire" and analyzed according to the Brazilian Healthy Eating Index-Revised adequacy, moderation, and overall scores. The adolescents' dietary intake was compared to the baseline 6 months and 12 months postintervention. Descriptive statistics and analyses of covariance were used, considering a 5\% significance level.

\section{Results}

Significant increases were found on the components total fruits $(F=6.98, p<0.01)$, total vegetables ( $F=5.76$, $p=0.02)$, beans $(F=5.96, p=0.02)$, and whole cereals $(F=12.35, p<0.001)$. However, there was also a significant decrease on the scores for milk and dairy $(F=6.48, p=0.02)$, and oils $(F=5.98, p=0.02)$. At 12-month post intervention, improvement on the overall score was found $(F=3.89, p=0.05)$, but there was a decrease on the component whole cereals $(F=11.85, p<0.001)$, as well as in milk and dairies $(F=6.38, p=0.02)$. Despite no significant effect for the SoFAAS component, a moderate effect size was revealed $(d=0.56)$.

\footnotetext{
1 Universidade de São Paulo, Faculdade de Saúde Pública, Departamento de Nutrição. São Paulo, SP, Brasil. Av. Dr. Arnaldo, 715 , Cerqueira César, 01246-904, São Paulo, SP, Brasil. Correspondence to: AC LEME. E-mail: <acarol.leme@gmail.com>.

Support: Fundação de Amparo à Pesquisa do Estado de São Paulo (Fapesp, Research Support Foundation of the São Paulo State) (Process n. 15/208532-7).
}

How to cite this article

Barco Leme AC, Tucunduca Phillip S, Fisberg RM. Changes in diet quality 6 and 12 months post-intervention: the Healthy Habits, Healthy Girls: Brazilian study. Rev Nutr. 2020;33:e1902184. https://doi.org/10.1590/1678-9865202033e190184 


\section{Conclusion}

There were significant effects on some diet quality components and for the overall scores at 6-month and 12-month post intervention. Therefore, sustainable dietary changes should be the focus of obesity prevention programs for adolescents. Socio-economic influences on diet behaviors would also need to be acknowledged.

Keywords: Adolescent. Diet. Healthy diet. Obesity. Prevention and control. Randomized controlled trial.

\section{R E S U M O}

\section{Objetivo}

Determinar a sustentabilidade da qualidade da alimentação presente em uma estratégia de prevenção à obesidade para adolescentes do sexo feminino.

\section{Métodos}

Ensaio randomizado controlado com 253 meninas (Média=15.61, 95\% Intervalo de confiança 15.51-15.72) matriculadas em 10 escolas técnicas de São Paulo. Por meio do "Questionário de Frequência Alimentar" a ingestão dietética foi determinada e analisada de acordo com os componentes de adequação, de moderação e de pontuação total do Índice da Qualidade da Dieta-Revisado. A ingestão dietética das adolescentes foi comparada na linha base, em 6 e em 12 meses após a intervenção. Estatística descritiva e análise de covariância foram utilizadas, considerando 5\% do nível de significância.

\section{Resultados}

Houve um aumento significativo nos componentes das frutas totais $(F=6.98, p<0.01)$, vegetais totais $(F=5.76$, $p=0.02$ ), feijões $(F=5.96, p=0.02)$ e cereais integrais $(F=12.35, p<0.001)$. Entretanto, houve expressiva redução para a pontuação dos componentes leite e derivados $(F=6.48, p=0.02)$ e óleos ( $F=5.98, p=0.02)$. Aos 12 meses de pós-intervenção, foi encontrada melhora na pontuação total do Índice da Qualidade da Dieta-Revisado ( $F=3.89, p=0.05)$, porém redução para os componentes cereais integrais $(F=11.85, p<0.001)$ e leites e derivados $(F=6.38, p=0.02)$. Apesar de não haver significância para os componentes gorduras sólidas, açúcar de adição e álcool, o tamanho de efeito moderado foi revelado ( $d=0.56)$.

\section{Conclusão}

Foram identificadas mudanças significativas para alguns componentes da qualidade da alimentação e da pontuação total aos 6 e aos 12 meses pós-intervenção. Mudanças dietéticas sustentáveis devem ser o foco de programas de prevenção para adolescentes. Além disso, influências socioeconômicas nos comportamentos dietéticos também devem ser consideradas.

Palavras-chave: Adolescentes. Dieta. Dieta saudável. Obesidade. Prevenção e controle. Ensaio clínico controlado aleatório.

\section{INTRODUCTION}

Behavioral school-based obesity prevention programs can intervene in energy balance behaviors to promote a healthy weight status by harmonizing diet and physical activity in adolescents between 10 and 19 years old [1,2]. Behavioral change interventions to prevent childhood obesity used theory-based strategies to promote sustainable diets and physical activity at short- and long-term [3]. Weight loss outcomes lasting for up to 2 years have been reported for adolescents who engaged in school-based behavioral obesity programs [4]. Nevertheless, it is uncertain whether their diet quality is also improving (which is the implicit goal of obesity prevention) or if adolescents are simply eating less, but having the same qualities of diet as they did prior to the programs [5]. This trend is common not only in high-income countries, but also in low- and middle-income countries, including Brazil $[6,7]$.

Analysis of daily nutrients or food intake have traditionally been studied in nutritional research, but adolescents do not consume these nutrients/foods separately; rather, food is eaten 
in a way structured by meals or snacks composed of a variety of foods, with complex combinations of nutrients that interact among themselves while facilitating or hindering the absorption of other nutrients [8]. Therefore, advances in the multiple etiologies of obesity and the health impacts of synergistic interactions among nutrients and other food have led to the increased interest in examining dietary patterns and obesity [9]. A growing body of literature reaches the associations between diet quality and health and disease, instead of applying single-nutrient-based approaches to disease risk $[10,11]$. Adherence to the recommended dietary patterns measured by diet quality indices, such as the Healthy Eating Index ( $\mathrm{HEI})$, has proven to be useful for overall diets in obesity prevention among teenagers $[9,12]$.

Overweight adolescents are more likely to become obese adults and this period in life is critical for interventions on lifestyle behaviors, especially diets, as adolescents are hypothesized to be more aware and independent of their own behaviors than younger children $[1,13]$. During the teenage years, changes in eating behaviors through a reduction of caloric intake may prevent excessive weight gain in the short-term, but not in long-term, when they may be consuming more food sources high in saturated fat, added sugars, and sodium, but less fruits, vegetables, skim milk and dairy products, lean meats, and whole-grains. In this approach, adolescents may be consuming less calories, but not necessarily having sustainable eating choices. It is worth mentioning that restricting calories, chronic dieting, and other weigh-control behaviors are shared risk factors for weight-related problems, i.e., obesity and eating disorders $[14,15]$.

The sustainability of obesity prevention programs to improve the teenagers' diet qualities in a longer-term perspective has not been extensively studied yet, especially in low- and middle-income countries. Thus, the purpose of this study was to determine the sustainability of the diet quality promoted by behavioral school-based prevention trial for adolescent girls 6 and 12 months after the intervention.

\section{METHODS}

This study was registered in ClinicalTrials.gov (NCT02228447) and reported according to the Consort checklist [16]. The ethics approval was obtained from the Institutional Review Board of the School of Public Health, University of São Paulo, Brazil (Protocol n. 01658112.6.0000.5421). Participants provided written informed consent.

Details of the study design, protocol, and participant characteristics at baseline were reported in detail elsewhere [17]. In summary, the Healthy Habits, Healthy Girls: Brazil (H3G-Brazil) study was a cluster randomized controlled trial with 253 adolescent girls and it included 10 public vocational schools (i.e., 5 intervention and 5 control schools) located in middle- and low-income communities in the city of São Paulo, Brazil.

The study's theoretical reference was Bandura's Social Cognitive Theory (SCT). The intervention components were developed using a taxonomy of behavior change strategies and designed to target psychological, behavioral, and environmental influences on nutrition and Physical Activity (PA): self-efficacy, social support, behavioral strategies, situations, outcome expectations (belief, as well as physical and cognitive benefits of healthy eating), and outcome expectancies (relevance of each expectation regarding the benefits) [18].

Each participant received a handbook that included 10 weeks of lifestyle-related information and home challenges designed to promote sustainable eating. Self-monitoring was employed for 
accompanying specific eating behaviors, as well as the daily servings of fruit and vegetables. A summary of how the program's nutrition messages were integrated to be delivered were provided in Chart 1. The chart also shows each HEl component used to evaluate how changes in the behaviors targeted by each message were ascertained. Moreover, three nutritional workshops were delivered in the school labs.

Chart 1. Diet quality evaluation based on the Brazilian Healthy Eating Index components: outcomes for H3G-Brazil weight-related program nutrition messages. São Paulo (SP), Brazil, 2015.

\begin{tabular}{|c|c|c|}
\hline Study week & Nutrition message & Dietary intake components \\
\hline 3 & Eat fruit and vegetables every day & $\begin{array}{l}\% \text { energy from total cereal, milk, and dairies, and } \\
\text { \# of servings/day }\end{array}$ \\
\hline 5 & Eat a healthy breakfast every day & $\begin{array}{l}\% \text { energy from overconsumed nutrients source* } \\
\% \text { energy from shortfall nutrients sources }\end{array}$ \\
\hline 7 & Eat less "junk food" and snack less & $\%$ energy from overconsumed nutrients sources ${ }^{*}$ \\
\hline 9 & $\begin{array}{l}\text { Drink water and replace SSB }{ }^{*} \text { with water, } 100 \% \text { juices, and } \\
\text { coconut water }\end{array}$ & $\%$ energy from added sugar sources \\
\hline 10 & Make family meals & $\begin{array}{l}\% \text { energy from overconsumed nutrients sources } \\
\% \text { energy from shortfall nutrients sources }\end{array}$ \\
\hline
\end{tabular}

Note: There were 10-week messages, one week a nutrition message was delivered and the other a physical activity message. For the purpose of this study only nutrition messages were added, but the physical activity messages were reported previously; \#: Number.

SSB: Sugar Sweetened Beverages (soft drinks, fruit drinks, and energy-drinks); ${ }^{*}$ Overconsumed nutrients: added sugars, saturated fats, and sodium; **Shortfall nutrients: Vitamin A, C, D and E, folate, calcium, magnesium and fiber, and iron for adolescent girls.

Other nutrition-focused prevention strategies included newsletters for parents and WhatsApp ${ }^{\circledR}$ group messages. Information and strategies to support the desired behaviors were provided (e.g., you should aim to consume five fruits/day. Have you eaten your fruit today? If so, tell me which fruits you have eaten and which one is your favorite). Four newsletters provided parents with feedback from the study, inexpensive recipes, and tips for replacing food sources high in energy, saturated fats, and added sugars with low in energy foods and sources of vitamins, fibers and minerals.

The sample size was based on changes in the Body Mass Index (BMI). The power calculation was based on $80 \%$ power, with a significance level of $5 \%$ (two-tailed), and an equal proportion of people exposed and non-exposed to the intervention. Considering the $20 \%$ drop-out rate, a total of 266 participants were necessary to detect a between-group difference in BMI of $0.4 \mathrm{~kg} / \mathrm{m}^{2}$ and 25 participants from each of the 10 schools were required.

The dietary intake was assessed using the Brazilian Food Frequency Questionnaire based on the Food Pyramid (BFFQ-FP) [19]. The BFFQ-FP was self-administered by adolescent girls in classrooms and supervised by trained research assistants (i.e., undergraduate and graduate students). Explanations were given when necessary and food and utensils displays (e.g., spoons and glasses) were provided to facilitate reporting their dietary intake into the BFFQ-FQ measures. The BFFQ-FP was a 50-item tool consisting of two parts: (1) a front page with food items of the eight food pyramid groups and (2) a back page with the Solid Fats, Alcohol, and Added Sugars (SoFAAS) items, such as sugar-sweetened beverages, sweets and candies, ready-to-eat cereals, hamburgers, French fries, and Brazilian salty pastries (deep-fried chicken cakes and cheese bread). The girls reported the frequency and amount 
eaten using household measures (units, cups, and spoons) of each item within the 12 last months. The seven categories were converted into daily frequency in times/day as follows: $\geq 2 \mathrm{x} /$ day $=2 ; 1 \mathrm{x} /$ day=1; 2-4x/week=0.43; $1 \mathrm{x} /$ week=0.14; $1-3 \mathrm{x} /$ month=0.07; $\leq 1 \mathrm{x} /$ month=0.02; Never $=0$.

To create diet quality scores, food items were selected based on the Brazilian Healthy Eating Index-Revised (BHEI-R) [20]. The Brazilian Healthy Eating Index-Revised is a measure of adherence to the Dietary Guidelines for the Brazilian population and is composed of 12 components, including nine adequacy components (total fruit, whole fruit, total vegetables, dark green and orange vegetables, and beans; total cereals; whole grains; milk and dairies; meat and eggs; and fatty acids) and three moderation components (Saturated Fat, Sodium, and SoFAAS [total calories obtained from solid fat, alcohol, and added sugar]). Higher scores for each component represent better diet qualities with moderation components scored reversely. The total BHEI-R score can theoretically range from 0 to 100, with 100 indicating perfect adherence. Prior to receiving the BFFQ-FP from the adolescents, the questionnaires were examined for rigor and precision, and the follow-up with the participants was completed as needed. The data obtained from the BFFQ-FQ was analyzed for intakes of energy, sodium, and fatty acids (MUFA, PUFA, SFA), using the software VirtualNutriPlus ${ }^{\circledR}$. The BFFQ-FQ were manually examined by a graduate student at the time of data analysis (Ph.D. level) for HEl adequacy and moderation components, after which they were converted to HEI equivalents. Given the time when the data was collected, the recommendations of food group servings provided by the Dietary Guidelines for the Brazilian Population 2006-2014 were adopted [21].

The descriptive statistics were computed for the group as a whole, as well as segmented by treatment condition. Continuous variables were presented as mean (with a 95\% confidence interval) and categorical variables as frequency (percentage). Differences between retention and drop-out rates at baseline for the diet quality index were tested with an independent sample t-test. Intention-to-treat analyses were considered for all outcome analyses. The effect of the intervention was determined using one-way Analysis of Covariance (Ancova) with 6-month and 12-month post-intervention values as the dependent variables (continuous variables), baseline values of the outcomes as covariates, and group (intervention vs. control) as the independent variable (fixed factor). Ancova is the preferred method of analysis in this situation because it provides an unbiased estimate of treatment effect [22-24]. Significance level of the main analyses was set to $p<0.05$. The data was analyzed using the SAS studio (SAS Institute Inc., Cary, NC, USA).

\section{R E S U L T S}

All 10 schools were retained in the study over the 12-month period, but 109 girls were not available for the follow-up assessments; 89 (62.7\%) and 55 (49.5\%) girls were retained in the intervention and control groups, respectively. There were no significant differences between retained and drop-out girls in relation to the dietary quality components and overall scores, except for the component "total cereals", regarding which participants who dropped out of the study or were not available for assessments had a lower score (mean [95\% Cl], 6.68 [6.18-7.19] vs. 5.84 [5.22-6.47], $p=0.04$ ) than study completers (Table 1 ). Details on the retention and drop-out rates of participants and on the differences between other variables were published elsewhere [7]. At baseline, 129 and 98 participants provided useable BFFQ-FP data in the intervention and control groups, respectively. Out of this number, 80 (Intervention Group) and 49 (Control Group) girls provided usable data at follow-up. 
Table 1. Dietary quality indexes of the study participants: retention vs. drop-out girls. São Paulo (SP), Brazil, 2015.

\begin{tabular}{|c|c|c|c|c|c|}
\hline \multicolumn{6}{|c|}{ Adequacy components } \\
\hline & \multicolumn{2}{|c|}{ Retention } & \multicolumn{2}{|c|}{ Drop-out } & \multirow{2}{*}{$p$-value } \\
\hline & Mean & $95 \% \mathrm{Cl}$ & Mean & $95 \% \mathrm{Cl}$ & \\
\hline Total fruits ${ }^{a}$ & 1.43 & $1.21-1.66$ & 1.44 & $1.16-1.72$ & 0.97 \\
\hline Whole fruits ${ }^{\mathbf{b}}$ & 2.27 & $1.99-2.54$ & 2.25 & $1.90-2.61$ & 0.95 \\
\hline Veveal $^{c}$ & 3.46 & $3.16-3.76$ & 3.49 & $3.14-3.84$ & 0.88 \\
\hline Beans & 4.52 & $4.32-4.73$ & 4.65 & $4.45-4.85$ & 0.39 \\
\hline Total Cereals ${ }^{\mathbf{d}}$ & 6.68 & $6.18-7.19$ & 5.84 & $5.22-6.47$ & 0.04 \\
\hline Whole Cereals ${ }^{\mathbf{e}}$ & 9.53 & $9.24-9.82$ & 9.81 & $9.60-10.01$ & 0.15 \\
\hline Milk and Dairy ${ }^{f}$ & 9.08 & $8.76-9.41$ & 9.19 & $8.83-9.55$ & 0.66 \\
\hline Meat, Eggs, Beans & 4.71 & $4.55-4.86$ & 4.82 & 4.68-4.95 & 0.29 \\
\hline Oils (ratio) ${ }^{\mathbf{g}}$ & 4.28 & $3.86-4.71$ & 3.99 & $3.55-4.44$ & 0.36 \\
\hline \multicolumn{6}{|c|}{ Moderation components } \\
\hline & \multicolumn{2}{|c|}{ Retention } & \multicolumn{2}{|c|}{ Drop-out } & \multirow{2}{*}{$p$-value } \\
\hline & Mean & $95 \% \mathrm{Cl}$ & Mean & $95 \% \mathrm{Cl}$ & \\
\hline Saturated fats & 7.69 & $7.11-8.28$ & 7.48 & $6.78-8.19$ & 0.65 \\
\hline Sodium & 9.42 & $9.08-9.76$ & 9.45 & $9.08-9.81$ & 0.89 \\
\hline SOFAAS & 17.39 & $16.69-18.08$ & 17.25 & $16.47-18.02$ & 0.79 \\
\hline Overall HEI score & 65.43 & $63.59-67.27$ & 65.45 & $63.84-67.05$ & 0.99 \\
\hline
\end{tabular}

Note: ${ }^{a}$ Including fruit and $100 \%$ juices; ${ }^{\mathbf{b}}$ Excluding $100 \%$ juices; ${ }^{c}$ Including beans only after maximum score for meat, eggs, and beans is reached; ${ }^{\mathbf{d}}$ Veveal: dark green and orange vegetables, and beans (only after maximum score for meat, eggs, and beans is reached); ${ }^{\mathbf{e}}$ Total grains: represent grains, cereals and starchy vegetables; ${ }^{\mathbf{I}}$ Including milk, dairy products, and alternatives (e.g. soy milk); ${ }^{9}$ Ratio for polyunsaturated and monounsaturated fatty acids, and solid fatty acids.

Cl: Confidence Interval; SoFAAS: Solid Fats, Added Sugars and Alcohol.

Baseline average age of the girls was 15.61 (95\% Confidence Interval [Cl] 15.51-15.72) years old. The majority self-describes as White/Caucasian (55.6\%) followed by mixed-race (26.3\%). Regarding their weights, $70.4 \%$ are at normal weight and $27.1 \%$ are either overweight or obese at baseline (Table 2). The sustainable changes of the Healthy Habits, Healthy Girls: Brazil (H3G-Brazil) study on body composition and other lifestyle behaviors are reported elsewhere [7]. In summary, the obesity prevention program for adolescent girls resulted in small non-significant reductions in BMI and in significant reductions in waist circumference, some sustainable significant differences for sedentary behaviors, but not significant for moderate-to-vigorous physical activity.

Table 3 reports the baseline, 6-month and 12-month post intervention changes in each diet quality component, as well as overall scores related to the key nutrition messages targeted during the H3G-Brazil. At 6-month post intervention there were significant effects on the components total fruits $(F=6.98, p<0.01, d=0.04)$, total vegetables $(F=5.76, p=0.02, d=0.17)$, beans ( $F=5.96, p=0.02, d=0.11)$, whole cereals $(F=12.35, p<0.001, d=0.19)$, milk and dairies ( $F=6.48, p=0.02, d=0.39$ ), and oils (ratio monounsaturated and polyunsaturated) ( $F=5.98$, $p=0.02, d=0.54)$. Although there was no significant change in the component saturated fats and sodium, the SoFAAS showed a moderate effect size ( $d=0.56$ and 0.54 , respectively).

Changes in the diet quality index components 12 months post-intervention were observed for whole cereals $(F=11.85, p<0.001, d=0.01)$ and milk and dairy $(F=6.38, p=0.02, d=0.33)$, along with changes in the overall score $(F=3.89, p=0.05, d=0.10)$ (Table 3). 
Table 2. Descriptive Statistics of the "Healthy Habits, Healthy Girls: Brazil study". São Paulo (SP), Brazil, 2015.

\begin{tabular}{|c|c|c|c|c|c|c|}
\hline \multicolumn{7}{|c|}{ Basiline } \\
\hline & \multicolumn{2}{|c|}{ Total Sample } & \multicolumn{2}{|c|}{ Intervention Group } & \multicolumn{2}{|c|}{ Control Group } \\
\hline & Mean & SD & Mean & SD & Mean & SD \\
\hline \multirow[t]{3}{*}{ Age } & 15.61 & $15.51-15.72$ & 15.90 & $15.74-16.00$ & 15.30 & $15.12-15.45$ \\
\hline & \multicolumn{2}{|c|}{ Total Sample } & \multicolumn{2}{|c|}{ Intervention Group } & \multicolumn{2}{|c|}{ Control Group } \\
\hline & $\mathrm{N}$ & $\%$ & $\mathrm{~N}$ & $\%$ & $\mathrm{~N}$ & $\%$ \\
\hline
\end{tabular}

\begin{tabular}{|c|c|c|c|c|c|c|}
\hline \multicolumn{7}{|l|}{ Race } \\
\hline Asian & 7 & 2.9 & 4 & 2.9 & 3 & 2.8 \\
\hline Native/First Nations & 2 & 0.8 & 2 & 1.5 & - & - \\
\hline Mixed-Race & 64 & 26.3 & 38 & 28.2 & 26 & 24.1 \\
\hline
\end{tabular}

Parental Educational Level

\begin{tabular}{|c|c|c|c|c|c|}
\hline Primary School & 16 & 6.6 & 8 & 5.9 & 8 \\
\hline Middle School & 30 & 12.4 & 21 & 15.6 & 9 \\
\hline High School & 87 & 35.8 & 60 & 44.4 & 27 \\
\hline Vocationl School & 29 & 11.9 & 16 & 11.9 & 13 \\
\hline Some College degree & 50 & 20.6 & 18 & 13.3 & 32 \\
\hline Graduate degree & 19 & 7.8 & 8 & 5.9 & 11 \\
\hline Don't know & 12 & 4.9 & 4 & 2.9 & 8 \\
\hline
\end{tabular}

\begin{tabular}{|c|c|c|c|c|c|c|}
\hline & \multicolumn{2}{|c|}{ Total Sample } & \multicolumn{2}{|c|}{ Intervention Group } & \multicolumn{2}{|c|}{ Control Group } \\
\hline & $\%$ & $\mathrm{Cl}$ & $\%$ & $\mathrm{Cl}$ & $\%$ & $\mathrm{Cl}$ \\
\hline \multicolumn{7}{|l|}{ Anthropometrics Mean } \\
\hline Weight (kg) & 57.86 & $56.84-59.37$ & 59.86 & $57.82-61.89$ & 55.30 & $53.09-57.50$ \\
\hline Height $(\mathrm{cm})$ & 1.61 & $1.60-1.62$ & 1.62 & $1.61-1.63$ & 1.60 & $1.59-1.61$ \\
\hline Waist Circumference $(\mathrm{cm})$ & 73.97 & $72.63-75.31$ & 75.93 & $74.19-77.67$ & 71.46 & $69.44-73.48$ \\
\hline BMI $\left(\mathrm{kg} / \mathrm{m}^{2}\right)$ & 22.23 & $21.73-22.73$ & 22.81 & $22.13-23.49$ & 21.49 & $20.77-22.21$ \\
\hline \multicolumn{7}{|l|}{ Weight Status } \\
\hline Underweight & 7 & 2.77 & 6 & 4.23 & 1 & 0.90 \\
\hline Normal Weight & 178 & 70.36 & 91 & 64.08 & 87 & 78.38 \\
\hline Overweight & 47 & 18.78 & 29 & 20.42 & 18 & 16.22 \\
\hline Obese & 21 & 8.30 & 16 & 11.27 & 5 & 4.50 \\
\hline \multicolumn{7}{|c|}{ Post-Intervention } \\
\hline & \multicolumn{2}{|c|}{ Total Sample } & \multicolumn{2}{|c|}{ Intervention Group } & \multicolumn{2}{|c|}{ Control Group } \\
\hline & $\%$ & $\mathrm{Cl}$ & $\%$ & $\mathrm{Cl}$ & $\%$ & $\mathrm{Cl}$ \\
\hline \multicolumn{7}{|l|}{ Anthopometrics Mean } \\
\hline Weight (kg) & 58.74 & $57.21-60.26$ & 60.55 & $58.51-62.59$ & 56.41 & $54.16-58.66$ \\
\hline Height & 1.61 & $1.61-1.62$ & 1.62 & $1.61-1.63$ & 1.61 & $1.59-1.62$ \\
\hline Waist Circumference $(\mathrm{cm})$ & 74.33 & $73.00-75.66$ & 75.81 & $74.10-77.52$ & 72.43 & $70.37-74.50$ \\
\hline $\mathrm{BMI}\left(\mathrm{kg} / \mathrm{m}^{2}\right)$ & 22.45 & $21.95-22.95$ & 22.99 & $22.30-23.67$ & 21.77 & $21.05-22.49$ \\
\hline \multicolumn{7}{|l|}{ Weight Status } \\
\hline Underweight & 4 & 1.58 & 4 & 2.82 & 0 & 0.00 \\
\hline Normal weight & 185 & 73.12 & 97 & 68.31 & 88 & 79.28 \\
\hline Overweight & 47 & 18.58 & 27 & 19.01 & 20 & 18.02 \\
\hline Obese & 17 & 6.72 & 14 & 9.86 & 5 & 2.70 \\
\hline \multicolumn{7}{|c|}{ 6-months follow-up } \\
\hline & \multicolumn{2}{|c|}{ Total Sample } & \multicolumn{2}{|c|}{ Intervention Group } & \multicolumn{2}{|c|}{ Control Group } \\
\hline & $\%$ & $\mathrm{Cl}$ & $\%$ & $\mathrm{Cl}$ & $\%$ & $\mathrm{Cl}$ \\
\hline \multicolumn{7}{|l|}{ Anthopometrics Mean } \\
\hline Weight (kg) & 58.14 & $56.45-59.84$ & 58.75 & $56.58-60.94$ & 56.94 & $54.07-58.81$ \\
\hline Height $(\mathrm{cm})$ & 1.61 & $1.60-1.62$ & 1.61 & $1.60-.163$ & 1.61 & $1.59-1.63$ \\
\hline
\end{tabular}


Table 2. Descriptive Statistics of the "Healthy Habits, Healthy Girls: Brazil study". São Paulo (SP), Brazil, 2015.

\begin{tabular}{|c|c|c|c|c|c|c|}
\hline \multicolumn{7}{|c|}{ 6-months follow-up } \\
\hline & \multicolumn{2}{|c|}{ Total Sample } & \multicolumn{2}{|c|}{ Intervention Group } & \multicolumn{2}{|c|}{ Control Group } \\
\hline & $\%$ & $\mathrm{Cl}$ & $\%$ & $\mathrm{Cl}$ & $\%$ & $\mathrm{Cl}$ \\
\hline Waist Circumference $(\mathrm{cm})$ & 76.31 & $74.89-77.48$ & 76.61 & 74.84-78.37 & 76.06 & $73.47-78.64$ \\
\hline $\mathrm{BMI}\left(\mathrm{kg} / \mathrm{m}^{2}\right)$ & 22.29 & $21.73-22.85$ & 22.51 & $21.77-23.24$ & 21.91 & $20.98-22.84$ \\
\hline \multicolumn{7}{|l|}{ Weight Status } \\
\hline Underweight & 3 & 2.03 & 2 & 2.22 & 1 & 1.82 \\
\hline Normal Weight & 115 & 77.70 & 68 & 75.56 & 44 & 80.00 \\
\hline Overweight & 22 & 14.86 & 14 & 15.56 & 8 & 14.55 \\
\hline Obese & 8 & 5.41 & 6 & 6.67 & 2 & 3.64 \\
\hline
\end{tabular}

Note: BMI: Body Mass Index; Cl: Confidence Interval; SD: Standart Deviation.

Table 3. Dietary Quality changes after the "Healthy Habits, Healthy Girls: Brazil" prevention program at immediate post-intervention and 6-month follow-up. São Paulo (SP), Brazil, 2015.

\begin{tabular}{|c|c|c|c|c|c|c|c|c|}
\hline \multicolumn{9}{|c|}{ Adequacy components } \\
\hline & & \multicolumn{2}{|c|}{ Intervention Group* } & \multicolumn{2}{|c|}{ Control Group** } & \multirow{2}{*}{ f-value } & \multirow{2}{*}{$p$-value } & \multirow{2}{*}{ Cohen's D } \\
\hline & & Mean & $\mathrm{Cl}$ & Mean & $\mathrm{Cl}$ & & & \\
\hline \multirow{2}{*}{ Total Fruits ${ }^{a}$} & Post-intervention & 2.31 & $2.06-2.57$ & 2.25 & $1.97-2.54$ & 6.98 & $<0.01$ & 0.04 \\
\hline & Follow-up & 2.16 & $1.80-2.52$ & 1.89 & $1.45-2.35$ & 0.15 & 0.70 & 0.16 \\
\hline \multirow{2}{*}{ Whole Fruits ${ }^{b}$} & Post-intervention & 3.54 & $3.26-3.83$ & 3.49 & $3.17-3.82$ & 2.83 & 0.09 & 0.03 \\
\hline & Follow-up & 3.08 & $2.69-3.47$ & 2.79 & $2.29-3.29$ & 0.73 & 0.39 & 0.15 \\
\hline \multirow{2}{*}{ Total Vegetables ${ }^{\mathbf{e}}$} & Post-intervention & 4.34 & $4.12-4.55$ & 4.09 & $3.80-4.39$ & 5.76 & 0.02 & 0.17 \\
\hline & Follow-up & 3.98 & $3.67-4.29$ & 3.71 & $3.28-4.13$ & 0.10 & 0.75 & 0.18 \\
\hline \multirow{2}{*}{ Veveal $^{\mathbf{d}}$} & Post-intervention & 4.73 & $4.56-4.89$ & 4.83 & $4.69-4.97$ & 5.96 & 0.02 & 0.11 \\
\hline & Follow-up & 4.56 & $4.31-4.81$ & 4.63 & $4.34-4.91$ & 0.04 & 0.85 & 0.06 \\
\hline \multirow{2}{*}{ Total Grains ${ }^{\mathbf{e}}$} & Post-intervention & 5.63 & $5.14-6.13$ & 6.57 & $6.09-7.04$ & 7.08 & $<0.01$ & 0.34 \\
\hline & Follow-up & 6.01 & $5.29-6.73$ & 7.18 & $6.38-7.98$ & 0.15 & 0.69 & 0.36 \\
\hline \multirow{2}{*}{ Whole Grains } & Post-intervention & 9.85 & $9.73-9.98$ & 9.62 & $9.31-9.92$ & 12.35 & $<0.001$ & 0.19 \\
\hline & Follow-up & 9.51 & $9.17-9.84$ & 9.49 & $9.12-9.87$ & 11.85 & $<0.001$ & 0.01 \\
\hline \multirow{2}{*}{ Milk and Dairy Product ${ }^{f}$} & Post-intervention & 9.13 & 8.79-9.46 & 9.75 & $9.56-9.94$ & 6.48 & 0.02 & 0.39 \\
\hline & Follow-up & 8.89 & $8.47-9.32$ & 9.48 & $9.15-9.82$ & 6.38 & 0.02 & 0.33 \\
\hline \multirow{3}{*}{ Meat, Eggs, Beans } & Post-intervention & 4.93 & $4.87-4.98$ & 4.93 & $4.86-4.99$ & 0.00 & 0.95 & 0.01 \\
\hline & Follow-up & 4.78 & $4.66-4.91$ & 4.77 & $4.60-4.95$ & 0.30 & 0.58 & 0.01 \\
\hline & Post-intervention & 4.15 & $3.71-4.57$ & 2.88 & $2.51-3.26$ & 5.98 & 0.02 & 0.54 \\
\hline Oils $^{\mathbf{g}}$ (ratio) & Follow-up & 3.59 & $3.01-4.16$ & 3.35 & $2.69-4.01$ & 0.05 & 0.82 & 0.09 \\
\hline \multicolumn{9}{|c|}{ Moderation components } \\
\hline & & \multicolumn{2}{|c|}{ Intervention Group* } & \multicolumn{2}{|c|}{ Control Group** } & f-value & o-value & Cohen's \\
\hline & & Mean & $\mathrm{Cl}$ & Mean & $\mathrm{Cl}$ & dive & galue & comers \\
\hline \multirow{2}{*}{ Saturated Fats } & Post-intervention & 6.06 & $5.42-6.70$ & 3.99 & $3.35-4.65$ & 0.83 & 0.36 & 0.56 \\
\hline & Follow-up & 5.69 & $4.93-6.47$ & 4.31 & $3.31-5.31$ & 0.87 & 0.35 & 0.38 \\
\hline \multirow{2}{*}{ Sodium } & Post-intervention & 9.18 & $8.81-9.55$ & 9.37 & $8.99-9.74$ & 1.20 & 0.27 & 0.09 \\
\hline & Follow-up & 9.02 & $8.52-9.52$ & 9.33 & $8.77-9.88$ & 0.11 & 0.75 & 0.13 \\
\hline \multirow{2}{*}{ SOFAAS } & Post-intervention & 16.00 & $15.35-16.67$ & 13.97 & 13.32-14.63 & 0.78 & 0.38 & 0.54 \\
\hline & Follow-up & 15.68 & $14.91-16.44$ & 14.28 & $13.27-15.28$ & 1.15 & 0.28 & 0.38 \\
\hline \multirow[b]{2}{*}{ Overall HEI Score } & Post-intervention & 78.57 & $77.40-79.75$ & 76.67 & $75.33-78.00$ & 0.32 & 0.57 & 0.27 \\
\hline & Follow-up & 72.48 & $70.89-74.07$ & 71.89 & $70.26-73.53$ & 3.89 & 0.05 & 0.08 \\
\hline
\end{tabular}

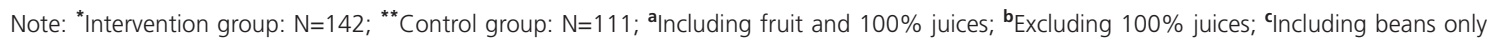
after maximum score for meat, eggs, and beans is reached; ${ }^{d}$ Veveal: dark green and orange vegetables, and beans (only after maximum score for meat, eggs, and beans is reached); ${ }^{\mathbf{e}}$ Total Grains: represent grains, cereals and starchy vegetables; ${ }^{\mathrm{f}}$ Including milk, dairy products and alternatives (e.g., soy milk); ${ }^{9}$ Ratio for polyunsaturated and monounsaturated fatty acids, and solid fatty acids.

SoFAAS: Solid Fats, Added Sugars and Alcohol.

\section{DISCUSSIO N}

The Healthy Habits, Healthy Girls: Brazil, a 6-month behavioral school-based obesity prevention program, showed a small decrease in energy consumption and improvement in some diet quality 
components at the 6-month and 12-month follow-up when compared to the control group. A previous study with a representative sample of 560 adolescents from the city of São Paulo reported a need for improvements in the overall diet quality $(M=50.33 \pm 0.42)$ [25], with similar findings for adolescents at baseline in the H3G: Brazil with an average score of $65.43 \pm 10.19$.

Although girls from the intervention group had significant improvements in the mean for total scores of BHEI-R from $65.85 \pm 6.08$ at baseline to $72.48 \pm 7.60$ at 12 -month post intervention, the index still needs to be improved [12]. Behavioral change programs should aim to improve the overall diet quality in order to provide sustainable dietary behaviors through adult life and thus reduce premature risk for obesity and other diet-related diseases (such as cardiovascular diseases, type 2 diabetes, and certain types of cancer) [1, 13]. Little evidence has reported the associations between diet-related diseases and a need for improvement in diet quality among children and adolescents due to the limited time for disease progression, but adults that presented higher overall diet quality scores have been related with lower risks for these diseases $[5,26]$.

The results of the present study indicate differences at 6-month post intervention and report improvements on diet quality for total fruits, total vegetables, and beans among girls that were exposed to the prevention program when compared to those who were not. Because intervention girls self-monitored their daily intake of fruit and vegetables, the non-significant difference in SoFAAS is not surprising [27]. However, a decrease in the intake of milk and dairy was observed, and not in other sugar-sweetened beverages, which is consistent with long-term findings on adolescents' diets. There was a reduction in the diet quality index for the component milk and dairy after the "H3G: Brazil" program, and the girls are not meeting the dietary guidelines recommendations for these products (less than one serving per day, on average). A qualitative study with five focus-group discussions conducted with 39 youth ( $M=22.5 \pm 1.8$ years, $75 \%$ girls) raised the issue of lactose intolerance and participants recognized that their friends placed themselves on dairy-free diets without seeking any medical advice. In particular, females reported that dairy products made them feel "really full" or "not too great" [28]. Hence, the current trends on diets for weight loss and/or other physical health goals, i.e., dairy-free and/or lactose-free diets, might have influenced the decrease on the intake of dairies products. Evidence from a randomized controlled trial with 240 US adolescents suggested that 2 cups of milk or the dairy equivalent is adequate for achieving a good health during this period of life, given the importance of this group as sources of calcium and vitamin D and in promoting bone health [29]. Therefore, behavioral change strategies should focus on self-monitoring sugar-sweetened beverages and on replacing them with milk beverages or other low-caloric beverages (e.g., 100\% juices, coconut water, and water).

Previous findings from the H3G: Brazil showed improvements in waist circumference at 6- and 12-month post intervention and this might have led to changes in some BHEI-R adequacy components at the 6-month follow-up [7]. Those who presented an increased intake of low-energy, fibers, vitamins, and minerals food sources experienced a reduction on central obesity when compared to those who consume more energy-dense, solid fats, and added sugars food sources $[7,10]$. In contrast, Polish teenagers (Mean Age $=11.9[95 \% \mathrm{Cl} 11.9-12]$ years old, $53.4 \%$ girls) presented a significant reduction in non-healthy dietary indexes (i.e., fast-foods, sweetened carbonated drinks, energy drinks, and sweets or confectionery), but no increase in pro-healthy dietary indexes (i.e., dairy products, fish, vegetables and fruits) after nutritional education program [10]. While the H3G: Brazil failed for moderation components, it improved for some adequacy components. A possible explanation for such contrast with the literature may be that the H3G: Brazil had a small family and parental involvement, while the study with Polish girls was based solely at the school level. Well- 
established family eating habits should be taken into account in obesity prevention programs, as parents (especially mothers) have the important role of acquiring food and preparing the meals for kids at home $[10,30,31]$. This suggests that in order to reduce the BHEI-R moderation components of older adolescents, activities should be directed towards reducing the availability of sugar-sweetened beverages, candies and sweets, and savory snacks at home.

Although for some of the index's components the H3G: Brazil showed some significance, other components did not show effects at long-term post-intervention. This has been previously reported by other studies [27]. Overall, the success rate of childhood obesity interventions presented mixed results, and one possible explanation for the failure of many obesity prevention interventions at long-term could be that simply offering information and education on dietary recommendations is insufficient, or maybe that dietary guidelines should be reformulated in order to be easily translated to the population and increase adherence [27]. Behavioral change needs health-promoting environments. Thus, sustainable eating habits should be combined in strategies that involve the school curriculum, parental support to encourage sustainable eating behaviors among high-school adolescents, and environmental (e.g., distance to green markets from the teen home) and cultural practices (e.g., mindful eating to provide a balance on eating behaviors, in order not to avoid their favorite foods that are part of the culture), promoting healthy lifestyle choices. The current study used self-monitoring for specific behaviors (e.g., increase in fruits and vegetables) and this can be a part of the content of obesity prevention programs. The identification of barriers and a restructured home environment are recognized as important factors in prevention programs that aim at promoting sustainable lifestyle behaviors, including diets [27]. Family-based prevention programs should be considered, as is wellknown that parents are important role models to their kids' habits, but also, kids can help model their families health habits [32]. For example, adolescents should help their parents on grocery shopping and preparing meals, and parents should not be the only ones responsible for these duties.

The strengths of this study include the recruitment of a diverse range of girls living in São Paulo, and conducting the intervention in schools located in low-income areas, making it easier for peers, school teachers, and parents support to enhance participation [7]. The core characteristics of the study design include theoretical-based, non-prescriptive behavioral change strategies, the use of mixed delivery modes (i.e., one week for diet and the other week for PA modes), and the low-intensity design, which minimizes participant and facilitator burden [17]. Facilitator training, delivery methods, and resources were standardized to ensure high fidelity to the program [7]. Limitations include self-report FFQs, which can result in misreporting, recall error, measurement error, and induce social desirability bias $[10,27]$. However, the FFQ used in this study was validated in comparison with three $24 \mathrm{~h}$ recalls and reproduced with Brazilian adolescents from vocational schools, and it has been shown to provide a useful method of measuring habitual dietary intake, which is generally acceptable as a main method of dietary intake in a study of this type and size [19].

\section{CONCLUSION}

The Healthy Habits, Healthy Girls: Brazil study improved the participants' intake of fruit and vegetables, beans and whole cereals, as measured by BHEI-R scores at 6-month post intervention, and presented an increase on overall diet quality at 12-month post intervention among girls that participated in the intervention, when compared to the control groups. However, there was a reduction in the milk and in the oil ratio at 6-month, and for whole cereals at 12-month post-intervention. There was not a significant decrease in the SoFAAS component at either time sets 
within the intervention condition. Sustainable diet changes should be the focus of obesity prevention programs for adolescent girls. It is important that intervention messages recognize that changes in diet should be taken gradually. Socio-economic influences on eating behaviors also would need to be acknowledged. The intervention would need to address eating everything in a balanced way through mindful approaches, not dichotomizing foods into bad and good. Moreover, intervention messages could be framed within adolescents' school and home environments, such as changes in the school canteen and having more family meals.

\section{ACKNOWLEDGEMENTS}

The authors would like to thank the students and teachers of the participating schools for the "Healthy Habits, Healthy Girls: Brazil" program.

\section{CONTRIBUTORS}

AC BARCO LEME contributed to the conception of the manuscript, data collection and analysis, and manuscript writing. S TUCUNDUVA PHILIPPI contributed to the conception of the manuscript and manuscript revision. RM FISBERG contributed to the analysis and data interpretation, and manuscript revision.

\section{REFERE NCES}

1. Aiello AM, Mello LM, Souza Nunes M, Silva AS, Nunes A. Prevalence of obesity in children and adolescents in Brazil: a meta-analysis of cross-sectional studies. Curr Pediatr Rev. 2015;11(1):36-42.

2. Yang L, Bovet $P, M a C$, Zhao M, Liang $Y, X i$ B. Prevalence of underweight and overweight among young adolescents aged 12-15 years in 58 low-income and middle-income countries. Pediatr Obes. 2019;14(3):e12468.

3. Militello LK, Kelly S, Melnyk BM, Smith L, Petosa R. A review of systematic reviews targeting the prevention and treatment of overweight and obesity in adolescent populations. J Adolesc Health. 2018;63(6):675-87.

4. Ash T, Agaronov A, Young T, Aftosmes-Tobio A, Davison KK. Family-based childhood obesity prevention interventions: a systematic review and quantitative content analysis. Int J Behav Nutr Phys Act. 2017;14(1):113.

5. Robson SM, Ziegler ML, McCullough MB, Stough CO, Zion C, Simon SL, et al. Changes in diet quality and home food environment in preschool children following weight management. Int J Behav Nutr Phys Act. 2019;16(1):16.

6. Ardic A, Erdogan S. The effectiveness of the COPE healthy lifestyles TEEN program: a school-based intervention in middle school adolescents with 12-month follow-up. J Adv Nurs. 2017;73(6):1377-89.

7. Leme ACB, Baranowski T, Thompson D, Nicklas T, Philippi ST. Sustained impact of the "Healthy Habits, Healthy Girls: Brazil" school-based randomized controlled trial for adolescents living in low-income communities. Prev Med Rep. 2018;10:346-52.

8. Santos RO, Fisberg RM, Marchioni DM, Baltar VT. Dietary patterns for meals of Brazilian adults. Brit J Nutr. 2015;114(5):822-8.

9. Wrobleski MM, Parker EA, Hurley KM, Oberlander S, Merry BC, Black MM. Comparison of the HEl and HEI-2010 diet quality measures in association with chronic disease risk among low-income, African American urban youth in Baltimore, Maryland. J Am Coll Nutr. 2018;37(3):201-8.

10. Wadolowska L, Hamulka J, Kowalkowska J, Ulewicz N, Hoffmann M, Gornicka M, et al. Changes in sedentary and active lifestyle, diet quality and body composition nine months after an education program in Polish students aged 11(-)12 years: report from the ABC of Healthy Eating Study. Nutrients. 2019;11(2). 
11. Tugault-Lafleur CN, Barr SI, Black JL. Examining differences in school hour and school day dietary quality among Canadian children between 2004 and 2015. Public Health Nutr. 2019;22(16):3051-62.

12. Krebs-Smith SM, Pannucci TE, Subar AF, Kirkpatrick SI, Lerman JL, Tooze JA, et al. Update of the Healthy Eating Index: HEl-2015. J Acad Nutr Diet. 2018;118(9):1591-602.

13. Ogata BN, Hayes D. Position of the academy of nutrition and dietetics: nutrition guidance for healthy children ages 2 to 11 years. J Acad Nutr Diet. 2014;114(8):1257-76.

14. Scaglioni S, De Cosmi V, Ciappolino V, Parazzini F, Brambilla P, Agostoni C. Factors influencing children's eating behaviours. Nutrients. 2018;10(6).

15. Haines J, Neumark-Sztainer D. Prevention of obesity and eating disorders: a consideration of shared risk factors. Health Educ Res. 2006;21(6):770-82.

16. Moher D, Hopewell S, Schulz KF, Montori V, Gotzsche PC, Devereaux PJ, et al. CONSORT 2010 explanation and elaboration: updated guidelines for reporting parallel group randomised trials. Br Med J. 2010;340:c869.

17. Leme AC, Philippi ST. The "Healthy Habits, Healthy Girls" randomized controlled trial for girls: study design, protocol, and baseline results. Cad Saúde Pública. 2015;31(7):1381-94.

18. Leme AC, Philippi ST. Cultural adaptation and psychometric properties of social cognitive scales related to adolescent dietary behaviors. Cad Saúde Coletiva. 2014;22:252-9.

19. Martinez MF, Philippi ST, Estima C, Leal G. Validity and reproducibility of a food frequency questionnaire to assess food group intake in adolescents. Cad Saúde Pública. 2013;29(9):1795-804.

20. Previdelli AN, Andrade SC, Pires MM, Ferreira SR, Fisberg RM, Marchioni DM. A revised version of the Healthy Eating Index for the Brazilian population. Rev Saúde Pblica. 2011;45(4):794-8.

21. Leme ACB, Fisberg RM, Thompson D, Philippi ST, Nicklas T, Baranowski T. Brazilian children's dietary intake in relation to Brazil's new nutrition guidelines: a systematic review. Curr Nutr Rep. 2019;8(2):145-66.

22. Winkens B, Van Breukelen GJ, Schouten HJ, Berger MP. Randomized clinical trials with a pre- and a posttreatment measurement: repeated measures versus ANCOVA models. Contemp Clin Trials. 2007;28(6):713-9.

23. Van Breukelen GJ. ANCOVA versus change from baseline: more power in randomized studies, more bias in nonrandomized studies [corrected]. J Clin Epidemiol. 2006;59(9):920-5.

24. De Boer MR, Waterlander WE, Kuijper LD, Steenhuis IH, Twisk JW. Testing for baseline differences in randomized controlled trials: an unhealthy research behavior that is hard to eradicate. Int J Behav Nutr Phy. 2015;12:4.

25. Andrade SC, Previdelli AN, Cesar CL, Marchioni DM, Fisberg RM. Trends in diet quality among adolescents, adults and older adults: a population-based study. Prev Med Rep. 2016;4:391-6.

26. Norte A, Sospedra I, Ortiz-Moncada R. Influence of economic crisis on dietary quality and obesity rates. Int J Food Sci Nutr. 2019;70(2):232-9.

27. Arvidsson L, Bogl LH, Eiben G, Hebestreit A, Nagy P, Tornaritis M, et al. Fat, sugar and water intakes among families from the IDEFICS intervention and control groups: first observations from I. Family. Obes Rev. 2015;16(Suppl 2):127-37.

28. Rouf A, Clayton S, Allman-Farinelli M. The barriers and enablers to achieving adequate calcium intake in young adults: a qualitative study using focus groups. J Hum Nutr Diet. 2019;32(4):443-54.

29. Vogel KA, Martin BR, McCabe LD, Peacock M, Warden SJ, McCabe GP, et al. The effect of dairy intake on bone mass and body composition in early pubertal girls and boys: a randomized controlled trial. Am J Clin Nutr. 2017;105(5):1214-29.

30. Robson SM, Couch SC, Peugh JL, Glanz K, Zhou C, Sallis JF, et al. Parent diet quality and energy intake are related to child diet quality and energy intake. J Acad Nutr Diet. 2016;116(6):984-90.

31. Haines J, Douglas S, Mirotta JA, O'Kane C, Breau R, Walton K, et al. Guelph Family Health Study: pilot study of a home-based obesity prevention intervention. Can J Public Health. 2018;109(4):549-60.

32. Haines J, Rifas-Shiman SL, Horton NJ, Kleinman K, Bauer KW, Davison KK, et al. Family functioning and quality of parent-adolescent relationship: cross-sectional associations with adolescent weight-related behaviors and weight status. Int J Behav Nutr Phys Act. 2016;13:68. 